\title{
Factors affecting the bond strength of denture base and reline acrylic resins to base metal materials
}

\author{
Naomi TANOUE ${ }^{1}$, Yasuhiro MATSUDA², Hiroaki YANAGIDA ${ }^{3}$, Hideo MATSUMURA ${ }^{4}$, Takashi SAWASE ${ }^{5}$ \\ 1- DDS, PhD, Assistant Professor, Division of Fixed Prosthodontics, Nagasaki University Hospital, Nagasaki, Japan. \\ 2- DT, PhD, Central Laboratory Center, Nagasaki University Hospital, Nagasaki, Japan. \\ 3- DDS, PhD, Assistant Professor, Department of Fixed Prosthodontics, Kagoshima University Graduate School of Medical and Dental Sciences School of \\ Dentistry, Kagoshima, Japan. \\ 4- DDS, PhD, Professor and Chair, Department of Fixed Prosthodontics, Nihon University School of Dentistry, Tokyo, Japan. \\ 5- DDS, PhD, Professor and Chair, Department of Applied Prosthodontics, Nagasaki University Graduate School of Biomedical Sciences, Nagasaki, Japan.
}

Corresponding address: Naomi Tanoue - Division of Fixed Prosthodontics - Nagasaki University Hospital, 1-7-1 - Sakamoto Nagasaki - 852-8501 - Japan - Phone: +81-95-819-7688 - Fax: +95-819-7689 - e-mail: t-naomi@nagasaki-u.ac.jp

Submitted: January 30, 2013 - Modification: April 04, 2013 - Accepted: May 15, 2013

\section{ABSTRACT}

O bjective: The shear bond strengths of two hard chairside reline resin materials and an auto-polymerizing denture base resin material to cast $\mathrm{Ti}$ and a $\mathrm{Co}-\mathrm{Cr}$ alloy treated using four conditioning methods were investigated. Material and Methods: Disk specimens (diameter $10 \mathrm{~mm}$ and thickness $2.5 \mathrm{~mm}$ ) were cast from pure $\mathrm{Ti}$ and $\mathrm{Co}-\mathrm{Cr}$ alloy. The specimens were wet-ground to a final surface finish of $600 \mathrm{grit}$, air-dried, and treated with the following bonding systems: 1 ) air-abraded with $50-70-\mu \mathrm{m}$ grain alumina $(\mathrm{CON})$; 2) 1) + conditioned with a primer, including an acidic phosphonoacetate monomer $($ MHPA $)$; 3) 1) + conditioned with a primer including a diphosphate monomer (MDP); 4) treated with a tribochemical system. Three resin materials were applied to each metal specimen. Shear bond strengths were determined before and after 10,000 thermocycles. Results: The strengths decreased after thermocycling for all combinations. Among the resin materials assessed, the denture base material showed significantly $(p<0.05)$ greater shear bond strengths than the two reline materials, except for the CON condition. After 10,000 thermocycles, the bond strengths of two reline materials decreased to less than $10 \mathrm{MPa}$ for both metals. The bond strengths of the denture base material with MDP were sufficient: $34.56 \mathrm{MPa}$ for cast $\mathrm{Ti}$ and 38.30 for $\mathrm{Co}-\mathrm{Cr}$ alloy. Conclusion: Bonding of reline resin materials to metals assessed was clinically insufficient, regardless of metal type, surface treatment, and resin composition. For the relining of metal denture frameworks, a denture base material should be used.

Key words: Chromium-cobalt alloys. Denture base. Denture rebasing. Shear strength. Titanium.

\section{INTRODUCTION}

In the manufacture of removable partial and complete dentures, adhesive bonding between the metal framework and the denture base is an important factor in the durability of the denture structure. Most of the adhesive bonding of the metal framework to the denture base material depends on mechanical fitting, which is effective enough for short-term use.

Gaps may occur between the framework and the residual mucous membrane when a denture has been used for a long time. In the case of metal base dentures, repairing the gap is clinically difficult. If the metal base denture can be repaired easily and firmly, the denture can be used for a long time. It is preferable if the metal base denture can be simply repaired using a resin material. However, for adhesive bonding of metal to a resin material in such a case, additional treatment for chemical adhesion is required.

Although there are many framework materials, 
commercially pure titanium ( $\mathrm{cp}-\mathrm{Ti}$ ) is preferred because of its suitable mechanical properties; cobalt-chromium (Co-Cr) alloys are also frequently used for denture frameworks because of their favorable mechanical properties. In the case of repairing metal base dentures fabricated with these metals as the framework, the surfaces should be effectively conditioned since reliable mechanical and chemical bondings are required for the denture to function properly ${ }^{6}$.

Many methods have been used to increase the bond strength of $\mathrm{cp}-\mathrm{Ti}$ and $\mathrm{Co}-\mathrm{Cr}$ frameworks. Airabrasion has been shown to effectively increase the strength between $\mathrm{cp}-\mathrm{Ti}$ and composite veneering materials ${ }^{4,21}$. Watanabe, et al. ${ }^{22}$ (1999) demonstrated the effectiveness of air-abrasion in increasing the bond strength of $\mathrm{cp}-\mathrm{Ti}$ to acrylic luting agents. Silanization is another method that improves the bonding properties of $\mathrm{cp}-\mathrm{Ti}^{8,9}$. According to Yoshida, et al. ${ }^{25}$ (2005), treatment with hydrogen peroxide and halogen-light irradiation provided favorable surface conditions with an appropriate oxide film thickness for enhancing the bond strength of $\mathrm{cp}-\mathrm{Ti}$ to acrylic luting agents. Treating the $\mathrm{cp}-\mathrm{Ti}$ surface with 1 $\mathrm{N} \mathrm{HCl}$ was reported to be effective for bonding to composite luting materials ${ }^{20}$. A spark-erosion bonding system was introduced as an easy and effective method for surface treatment of Co$\mathrm{Cr}$ alloys or $\mathrm{cp}-\mathrm{Ti}$ to improve the bonding to composite veneering materials ${ }^{5}$. In addition to the above treatments, chemical treatments using functional monomers after air-abrasion is also useful for enhancing the adhesive performance of $\mathrm{cp}-\mathrm{Ti}^{10,11,19,23}$ and $\mathrm{Co}-\mathrm{Cr}$ alloys ${ }^{11,12}$. For enhancing the bond strengths of $\mathrm{Ti}$ and $\mathrm{Co}-\mathrm{Cr}$ alloys to heatand auto-polymerizing denture base resins, the use of metal conditioners is also effective ${ }^{13,17}$.
According to Matsuda, et al. ${ }^{11}$ (2010), air-abrasion and treatment with a diphosphate monomer was most effective for both the $\mathrm{Cp}-\mathrm{Ti}$ and $\mathrm{Co}-\mathrm{Cr}$.

Various types of resin materials can be used for repairs, e.g., heat-polymerizing denture base resins, auto-polymerizing resins, hard reline acrylic resins, and soft reline materials. Reline materials are newer than the other materials, but the reliabilities of their properties have already been reported ${ }^{1,14,16,24}$. However, only limited information is available regarding the factors affecting the bond strength between base metals for denture frameworks and these materials for repairs.

The aim of the present study is to evaluate the adhesion of a pour-type auto-polymerizing denture base material and two reline resin materials to $\mathrm{cp}$ $\mathrm{Ti}$ and a Co-Cr alloy conditioned using four metal surface treatments. The hypothesis of the present study was that the type of denture framework material, resin material, and treatment would influence the shear bond strength between the resins and the base metal framework.

\section{MATERIAL AND METHODS}

Two hard chairside reline resin materials and an auto-polymerizing denture base resin material were assessed in this study. Information on the resin materials used is presented in Figure 1.

A Co-Cr alloy (JD Alloy, Co 63.0, $\mathrm{Cr} 28.5$, Mo 6.0 , others 2.5 mass\%, Heraeus Kulzer $\mathrm{GmbH}$; Hanau, Germany) and a cp-Ti (T-Alloy H, GC Corp.; Tokyo, Japan) designed for denture frameworks and cast restorations were used as adherent materials. Two hundred and sixteen disk-shaped specimens $(10 \mathrm{~mm}$ in diameter and $2.5 \mathrm{~mm}$ in thickness) were cast from the Co-Cr alloy and $\mathrm{cp}$ $\mathrm{Ti}$, respectively, according to the manufacturers'

\begin{tabular}{|c|c|c|c|c|c|c|}
\hline Product & Code & \multicolumn{2}{|c|}{ Composition } & $\begin{array}{c}\text { Powder/liquid } \\
\text { ratio (g/ml) }\end{array}$ & $\begin{array}{c}\text { Polymerization } \\
\text { status }\end{array}$ & Manufacturer \\
\hline & & Powder & Liquid & & & \\
\hline Denture Liner & DL & PEMA & IBMA, MAATE & $1.70 / 1.0$ & $\begin{array}{c}5.5 \text { min at room } \\
\text { temperature }\end{array}$ & Shofu Inc. \\
\hline & & & & & & \\
\hline $\begin{array}{c}\text { Tokuyama } \\
\text { Rebase II }\end{array}$ & TR & PEMA & $\begin{array}{c}1.9-N A D M A \\
\text { 2-AAEMA }\end{array}$ & $2.06 / 1.0$ & $\begin{array}{c}5.5 \text { min at room } \\
\text { temperature }\end{array}$ & $\begin{array}{c}\text { Tokuyama Dental } \\
\text { Corp. }\end{array}$ \\
\hline & & & & & & 15 min at $55^{\circ} \mathrm{C}$ \\
\hline Palapress Vario & PV & PMMA & $\begin{array}{c}\text { MMA, } \\
\text { under } 0.2 \mathrm{MPa} \\
\text { pressure }\end{array}$ & $\begin{array}{c}\text { Heraeus Kulzer } \\
\text { GmbH }\end{array}$ \\
\hline
\end{tabular}

PEMA=poly(ethyl methacrylate); IBMA=isobutyl methacrylate; MAATE=methacrylic acid triester; 1,9-NADMA=1,9nonanediol dimethacrylate; 2-AAEMA=(acetoacetoxy) ethyl methacrylate, $M M A=$ methyl methacrylate, 1,4-BuDMA=1,4butanediol dimethacrylate. TMBA=trimethyl barbituric acid

Figure 1- Resin materials used in this study 


\begin{tabular}{|c|c|c|c|c|}
\hline \multicolumn{2}{|c|}{ Trade Name } & Manufacturer & Lot No. & Component/Information \\
\hline \multirow{2}{*}{ Primer } & $\begin{array}{c}\text { AZ Primer } \\
\text { Estenia Opaque } \\
\text { Primer }\end{array}$ & $\begin{array}{c}\text { Shofu Inc. } \\
\text { Kuraray Noritake } \\
\text { Dental Inc. }\end{array}$ & $\begin{array}{c}20701 \\
\text { 00150B }\end{array}$ & $\begin{array}{c}\text { MHPA, acetone } \\
\text { MDP, solvent }\end{array}$ \\
$\begin{array}{c}\text { Rocatec Pre } \\
\text { Rystem }\end{array}$ & Rocatec Plus & 3M ESPE & 279500 & $\begin{array}{c}110-\mu \text { particle alumina } \\
110-\mu m \text { particle alumina } \\
\text { coated with silica based } \\
\text { composite } \\
\text { Y-MTPS, ethanol }\end{array}$ \\
\hline
\end{tabular}

Figure 2- Treatments assessed in this study

specifications. The 216 disks were ground with No. 600 silicon-carbide abrasive paper and divided into four sets of 54 disks.

Of the four sets, three sets (162 disks) were air-abraded with 50-70- $\mu \mathrm{m}$ alumina (Hi-Aluminas, Shofu Inc.; Kyoto, Japan) for $10 \mathrm{~s}$ (Jet Blast II, J. Morita Corp.; Suita, Japan). The air pressure was $0.5 \mathrm{MPa}$ and the distance of the nozzle from the metal surface was approximately $5 \mathrm{~mm}$. One of the three sets (54 disks) was left unprimed as a control (CON). In two of the three air-abraded sets, one of two primers (AZ Primer, Shofu Inc. or Estenia Opaque Primer, Kuraray Noritake Dental Inc.; Tokyo, Japan) was applied to the metal surface using a sponge pellet. Both primers include acid functional monomers, but of different types. Information on the primers used is presented in Figure 2. The two treatments are denoted by MHPA and MDP since the AZ primer contains an acidic phosphonoacetate monomer (MHPA), and the Estenia Opaque Primer includes a diphosphate monomer (MDP) as the functional monomers. The remaining set was air-abraded with $110-\mu \mathrm{m}$ alumina, air-abraded with $110-\mu \mathrm{m}$ alumina coated with a silica-based composite, and primed with a silane coupling agent (Rocatec system, 3M ESPE; St. Paul, MN, USA; TC). Information on the primers used is also presented in Figure 2. A total of 54 specimens were prepared for each combination of metal and surface treatment.

A piece of tape with a hole of $5 \mathrm{~mm}$ diameter and $50 \mu \mathrm{m}$ thickness was placed on the surface of the specimen to define the bonding area. A brass ring ( $6 \mathrm{~mm}$ inside diameter, $2 \mathrm{~mm}$ length, and $1 \mathrm{~mm}$ wall thickness) was placed around the hole and filled with one of the three resins. The resin materials were polymerized according to the manufacturer's instructions (Figure 1). After polymerization, the specimens were immersed in water at $37^{\circ} \mathrm{C}$ for $24 \mathrm{~h}$, and this state was defined as thermocycle 0 . The 18 disks were then divided into two groups of nine specimens each. Half (12 sets of nine) of the disks were tested for 24-h, shear bond strength at thermocycle 0 , and the remaining specimens were placed in a thermocycling apparatus (Thermocycling Machine, RKC Instrument Inc.; Tokyo, Japan) and cycled between water at $4^{\circ} \mathrm{C}$ and $60^{\circ} \mathrm{C}$, with a $1^{\text {-min }}$ dwelltime per bath, for 10,000 cycles.

The specimens were embedded in acrylic resin molds, and seated in an ISO/TR 11405 shear testing jig. Shear bond strengths were determined using a mechanical testing device (AGS-10kNG, Shimadzu; Kyoto, Japan) at a cross-head speed of $0.5 \mathrm{~mm} / \mathrm{min}$. For each set of specimens, the mean shear bond strength, standard deviation (SD), and the rate of decrease in bond strength with thermocycling were calculated. To determine the influence of the resin materials, the values were compared using the Steel-Dwass tests for each condition with the value of statistical significance set at $\alpha=0.05$.

For the MDP and TC treatments after thermocycling, the values were compared using two-way analysis of variance (ANOVA) with the value of statistical significance set at $\alpha=0.05$. All analyses were carried out using the SPSS 15.0 for Windows (SPSS Japan Inc; Tokyo, Japan).

\section{RESULTS}

The shear bond strength and Steel-Dwass test results at 0 and 10,000 thermocycles are given in Table 1. The strengths decreased after thermocycling for all combinations. Among the resin materials assessed, the PV denture base material showed significantly $(p<0.05)$ greater shear bond strengths than the two reline metals ( $D L$ and TR), except for the CON condition. In the case of the 10,000 thermocycling status in particular, the bond strengths of the DL and TR materials significantly decreased to less than $10 \mathrm{MPa}$ for both metals. In contrast, the bond strength of the PV with MDP was sufficient, even after thermocycling: $34.56 \mathrm{MPa}$ for $\mathrm{cp}-\mathrm{Ti}$ and 38.30 for the $\mathrm{Co}-\mathrm{Cr}$ alloy. The rates of decrease with thermocycling are shown in Table 2, and the decrease rate for the PV with MDP is the lowest: $19.93 \%$ for $\mathrm{cP}-\mathrm{Ti}$ and 25.60 for Co-Cr. Regarding bonding of the two reline materials, TC showed the 
Table 1- Bond strength results (MPa)

\begin{tabular}{|c|c|c|c|c|c|}
\hline & Status & & DL & TR & PV \\
\hline \multirow[t]{8}{*}{0 cycle } & $\mathrm{CON}$ & $\mathrm{cp}-\mathrm{Ti}$ & $8.27(1.41)^{a}$ & $10.95(1.60)^{b}$ & $9.97(3.09)^{\mathrm{ab}}$ \\
\hline & & $\mathrm{Co}-\mathrm{Cr}$ & $7.68(1.25)^{a}$ & $12.51(4.10)^{b}$ & $12.13(1.66)^{b}$ \\
\hline & MHPA & $\mathrm{cp}-\mathrm{Ti}$ & $30.49(4.22)^{a}$ & $24.52(1.36)^{b}$ & $46.91(3.72)^{c}$ \\
\hline & & $\mathrm{Co}-\mathrm{Cr}$ & $32.32(4.09)^{a}$ & $26.30(2.53)^{b}$ & $48.20(6.70)^{c}$ \\
\hline & MDP & $\mathrm{cp}-\mathrm{Ti}$ & $28.67(4.25)^{a}$ & $23.17(3.25)^{b}$ & $43.16(2.75)^{c}$ \\
\hline & & $\mathrm{Co}-\mathrm{Cr}$ & $31.00(3.27)^{\mathrm{a}}$ & $28.2(2.86)^{\mathrm{a}}$ & $51.48(6.14)^{\mathrm{b}}$ \\
\hline & $\mathrm{TC}$ & $\mathrm{cp}-\mathrm{Ti}$ & $23.12(3.57)^{\mathrm{a}}$ & $23.18(2.91)^{a}$ & $38.49(5.49)^{b}$ \\
\hline & & $\mathrm{Co}-\mathrm{Cr}$ & $15.01(3.22)^{a}$ & $38.49(5.49)^{b}$ & $30.20(3.25)^{c}$ \\
\hline \multirow[t]{8}{*}{10,000 cycles } & CON & $\mathrm{cp}-\mathrm{Ti}$ & $0.50(0.31)^{a}$ & $0.12(0.05)^{b}$ & $1.44(0.76)^{c}$ \\
\hline & & $\mathrm{Co}-\mathrm{Cr}$ & $0.32(0.16)^{a}$ & $0.25(0.04)^{b}$ & $0.83(0.53)^{c}$ \\
\hline & MHPA & $\mathrm{cp}-\mathrm{Ti}$ & $0.38(0.19)^{a}$ & $0.40(0.18)^{a}$ & $21.46(1.72)^{b}$ \\
\hline & & $\mathrm{Co}-\mathrm{Cr}$ & $0.50(0.24)^{a}$ & $0.30(0.23)^{a}$ & $21.16(5.84)^{b}$ \\
\hline & MDP & $\mathrm{cp}-\mathrm{Ti}$ & $0.50(0.09)^{a}$ & $1.89(0.77)^{b}$ & $34.56(3.01)^{c}$ \\
\hline & & $\mathrm{Co}-\mathrm{Cr}$ & $0.29(0.13)^{a}$ & $0.69(0.62)^{a}$ & $38.30(3.66)^{b}$ \\
\hline & TC & $\mathrm{cp}-\mathrm{Ti}$ & $4.19(1.88)^{a}$ & $4.57(1.41)^{a}$ & $12.22(1.97)^{b}$ \\
\hline & & $\mathrm{Co}-\mathrm{Cr}$ & $1.21(1.00)^{a}$ & $1.27(0.93)^{\mathrm{a}}$ & $9.43(0.90)^{\mathrm{b}}$ \\
\hline
\end{tabular}

( ): standard deviations. Same superscript letters indicate insignificant difference with in the same column $(p<0.05)$

Table 2- Decrease rates of bond strength with thermocycling

\begin{tabular}{cccccc}
\hline & & CON & MHPA & MDP & TC \\
\hline DL & $\mathrm{cp}-\mathrm{Ti}$ & 93.96 & 98.75 & 98.26 & 81.88 \\
& $\mathrm{Co}-\mathrm{Cr}$ & 95.83 & 98.75 & 99.06 & 91.94 \\
$\mathrm{TR}$ & $\mathrm{cp}-\mathrm{Ti}$ & 98.9 & 98.37 & 91.84 & 80.28 \\
& $\mathrm{Co}-\mathrm{Cr}$ & 98,00 & 98.86 & 97.55 & 94.17 \\
$\mathrm{TV}$ & $\mathrm{cp}-\mathrm{Ti}$ & 85.56 & 54.25 & 19.93 & 68.25 \\
& $\mathrm{Co}-\mathrm{Cr}$ & 93.16 & 56.1 & 25.6 & 68.77 \\
\hline
\end{tabular}

Unit: \%

Table 3- Results of two-way factorial ANOVA

\begin{tabular}{cccccc}
\hline & Source of variation & df & Sum of squares & F-value & P value \\
\hline MDP treatment & Metal (cp-Ti / Co-Cr) & 1 & 8.08 & 2.07 & 0.1566 \\
& Resin (DL / TR / PV) & 2 & 15205.32 & 1947.67 & $<.0001^{*}$ \\
& Metal / Resin & 2 & 61.29 & 7.85 & $0.0011^{*}$ \\
TC treatment & Metal (cp-Ti / Co-Cr) & 1 & 123.65 & 61.54 & $<.0001^{*}$ \\
& Resin (DL / TR / PV) & 2 & 771.48 & 191.98 & $<.0001^{*}$ \\
& Metal / Resin & 2 & 0.58 & 0.14 & 0.8668 \\
\hline
\end{tabular}

\footnotetext{
* : significant
}

lowest decrease rate for both metals.

The MDP and TC treatments showed characteristic tendencies, and the factors influencing the results after thermocycling were examined using two-way (metal and resin types) factorial ANOVAs (Table 3). Regarding the MDP, the metal type factor was not statistically significant $(p<0.05)$, although the resin type and its interactions were significant. In the case of the TC, the metal and resin factors were statistically significant $(p<0.05)$, although their interaction was not significant.

\section{DISCUSSION}

Although the denture base resin and metal framework are substantially joined using a 
mechanical retentive device, additional chemical bonding to the framework is necessary in the case of repairs. When using a metal base as the framework, air-abrasion followed by treatment with an acidic functional monomer is a well-known and useful method for mechanical and chemical adhesions between the metal and the resin6. However, the tribochemical system, i.e., TC, used in this study might also be effective, since TC mechanochemical bonding occurs for both noble and base metals. Air-abrasion, air-abrasion and treatment with two acidic primers, and the TC system were therefore selected for evaluation.

Thermocycling was used as an accelerated aging test to evaluate the consistency and durability of each surface treatment, and the results after thermocycling might be more significant when considering the situation of a removable denture in the oral cavity. The results showed that for a thermocycling 10,000 status, only air-abrasion and treatments with the two acidic primers were effective denture base material treatments, irrespective of the metal materials. Palapress Vario denture-base material, which is the classic cold-curing denture acrylic material, is often used indirectly out of the oral cavity for repair work, because its polymerization takes time.

The bond strengths of the two reline materials ( $D L$ and TR) were too low to be influenced by the type of metal material and treatment, and the decrease rates for the acidic monomer conditions (MHPA and MDP) with thermocycling were more than $90 \%$. The rate for the TC condition was not as high as those for the acidic monomer conditions, but was still more than $80 \%$. This shows that an acrylic reline material is quite unsuitable for the repair of a metal framework. As seen from the compositions in Figure 1, the TR material, which characteristically includes 1.9-NADMA for cross-linking, was able to form stronger polymer networks than the DL was. Yatabe, et al. ${ }^{24}$ (1999) reported that highly polymerized and cross-linked reline materials are harder than conventional reline materials. Takahashi, et al. ${ }^{18}$ (2000) evaluated the strength of relined denture base materials subjected to long-term water immersion, and reported that the flexural strength of a relined base material was dependent on the strength of the type of denture base polymer and that of the reline polymer. The results for the two types of reline materials were not significantly different in this study. Cucci, et al. ${ }^{2}$ (1999) evaluated the tensile bond strengths of reline materials influenced by water storage and reported that the bonding between the denture base resin and reline materials failed in only $50 \mathrm{~h}$. They reported that these failures were caused by the effects of water, differences between the mechanical properties of the resin materials, and so on. Obviously, the mechanical characteristics such as the coefficient of thermal expansion of the metal material and the resin are different.

However, this study has some limitations. First, the methods used for polymerization of the three materials used in this study are different, since they were polymerized in accordance with the manufacturers' instructions. The polymerization conditions are one of the factors that can influence the test results. Second, there was no mechanical retention on the metal surfaces. This means that the experimental method used in this study did not reproduce the clinical situation. These factors might affect the results (values).

The two priming agents assessed contain a phosphorus-based acidic functional monomer (Figure 2). When comparing the bonding performances of the two primers to the denture base PV material, the MDP was more effective than the MHPA. Matsuda, et al. ${ }^{11}$ (2010) evaluated the bonding performances of MDP and MHPA, and reported that MDP was more effective for bonding to $\mathrm{cp}-\mathrm{Ti}$ and $\mathrm{Co}-\mathrm{Cr}$ frameworks. This might be caused by differences between the functional monomers. The MDP functional monomer is well known to be effective in adhesive bonding to base metals ${ }^{12,13,17}$; the hydrogen phosphate group chemically bonds to metal oxides, including titanium oxide on $\mathrm{cp}-\mathrm{Ti}$ and cobalt and chromium oxides on Co-Cr. Nevertheless, with respect to the two reline materials, neither of the primers was effective for bonding. This shows that the reline materials are undesirable for use in the repair of a base metal framework, regardless of the superiority or inferiority of the performance of the functional monomer. According to Matsuda, et al. ${ }^{11}$ (2010), mixed failure (a combination of cohesive and adhesive failure) was observed in most specimens treated with MDP. This shows the high reliability of the MDP treatment for the base metal. The low values for the reline materials in this study might therefore not be caused by chemical bonding using the acidic functional monomer but by the material itself. Actually, many mechanical properties of reline materials are inferior to those of base materials ${ }^{3}$. Zissis, et al. ${ }^{26}$ (2008) evaluated the release of residual monomer from denture base resins and reline materials and reported that the heat-polymerizing denture base acrylic resins released insignificant amounts of residual monomer during the storage period, but both the auto-polymerizing denture base resin and the reline material released significant amounts of residual monomer during the initial storage period. The denture base resin used in this study is not a heat-polymerizing material, but, considering the polymerization status indicated in Figure 1 , it is 
assumed to be more highly polymerized than the other two materials.

In the current study, the TC system, which uses impact energy to apply a silicate coating to the metal surface, was comparatively effective in enhancing the bond strength between the reline materials and frameworks. As has been noted, the reline materials are unsuitable for metal framework repairs. However, the decrease rate of TC was slightly lower, i.e., the performance of the TC was slightly better, than those of the other treatments. The TC values after thermocycling were not high, but were significantly affected by the type of both the metal and the resin. This tendency was different from the results for the MDP condition (Table 3). The particle size of alumina for air-abrasion was 50-70 $\mu \mathrm{m}$ for the CON, MDP, and MHPA, but that for the TC was $110 \mu \mathrm{m}$. The greater unevenness produced by the larger alumina particles might create stronger mechanical interlocks between the resin and metal material. Considering the results for the two acidic primers (MDP and MHPA), it is supposed that the chemical effect in the TC was also low. The reason why the influence of the metal type was significant under the TC conditions is that the values for TC were generally lower and that the slight difference between the mechanical properties $^{15}$ of the two metals was related to the mechanical retention. However, the highest values obtained with the TC-PV combination after 10,000 thermocycles were around $10 \mathrm{MPa}$; these are lower than those obtained for acidic monomers and in other similar studies ${ }^{6,7}$.

Within the limitations of this study, it is suggested that a denture base resin rather than a reline material should be selected for repair of a removable denture with a base metal framework. Also, as preprocessing for bonding with the denture base resin, the MDP treatment (air-abrasion and priming with MDP functional monomer) is recommended, regardless of the metal type.

\section{CONCLUSION}

Based on the results and limitations of this study, the following conclusions were drawn. When using a denture-base resin, treatment with air-abrasion and conditioning with a diphosphate functional monomer were effective for enhancing bonding durability to both cast $\mathrm{Ti}$ and a $\mathrm{Co}-\mathrm{Cr}$ alloy.

\section{ACKOWLEDGEMENTS}

This study was supported in part by a Grant-inAid for Scientific Research, (C) 23592858 (20112013), 23592862 (2011-2013), and 21592474 (2009-2011) from the Japan Society for the Promotion of Science (JSPS).

\section{REFERENCES}

1- Chaves CA, Machado AL, Vergani CE, Souza RF, Giampaolo ET. Cytotoxicity of denture base and hard chairside reline materials: a systematic review. J Prosthet Dent. 2012;107:114-27.

2- Cucci AL, Rached RN, Giampaolo ET, Vergani CE. Tensile bond strengths of hard chairside reline resins as influenced by water storage. J Oral Rehabil. 1999;26:631-4.

3- Finoti LS, Machado AL, Chaves CD, Pavarina AC, Vergani CE. Effect of long-term water immersion on the fracture toughness of denture base and reline resins. Gerodontology. 2012;29:e85864.

4- Fujishima A, Fujishima Y, Ferracane JL. Shear bond strength of four commercial bonding systems to cp Ti. Dent Mater. 1995; 11:82-6.

5- Janda R, Roulet JF, Latta M, Damerau G. Spark erosion as a metal-resin bonding system. Dent Mater. 2007;23:193-7.

6- Kawaguchi T, Shimizu H, Lassila LV, Vallittu PK, Takahashi Y. Effect of surface preparation on the bond strength of heatpolymerized denture base resin to commercially pure titanium and cobalt-chromium alloy. Dent Mater J. 2011;30:143-50.

7- Lim HP, Kim SS, Yang HS, Vang MS. Shear bond strength and failure types of polymethyl methacrylate denture base resin and titanium treated with surface conditioner. Int J Prosthodont. 2010;23:246-8.

8- Matinlinna JP, Lassila LV, Kangasniemi I, Yli-Upro A, Vallittu PK. Shear bond strength of Bis-GMA resin and methacrylated dendrimer resins on silanized titanium substrate. Dent Mater. 2005;21:287-96.

8- Matinlinna JP, Lassila LV, Vallittu PK. The effect of a novel silane blend system on resin bond strength to silica-coated Ti substrate. J Dent. 2006;34:436-43.

9- Matinlinna JP, Ozcan M, Lassila LV, Vallittu PK. The effect of a 3-methacryloxypropyltrimethoxysilane and vinyltriisopropoxysilane blend and tris(3-trimethoxysilylpropyl) isocyanurate on the shear bond strength of composite resin to titanium metal. Dent Mater. 2004;20:804-13.

10- Matsuda Y, Yanagida H, Ide T, Matsumura H, Tanoue N. Bond strength of poly(methyl methacrylate) denture base material to cast titanium and cobalt-chromium alloy. J Adhes Dent. 2010;12:223-9.

11- Matsumura H, Tanaka T, Taira Y, Atsuta M. Bonding of a cobaltchromium alloy with acidic primers and tri-n-butylborane-initiated luting agents. J Prosthet Dent. 1996;76:194-9.

12- Ohkubo C, Watanabe I, Hosoi T, Okabe T. Shear bond strengths of polymethyl methacrylate to cast titanium and cobaltchromium frameworks using five metal primers. J Prosthet Dent. 2000;83:50-7.

13- Pinto LR, Acosta EJ, Távora FF, Silva PM, Porto VC. Effect of repeated cycles of chemical disinfection on the roughness and hardness of hard reline acrylic resins. Gerodontology. 2010;27:147-53.

14- Rodrigues RC, Almeida EP, Faria AC, Macedo AP, Mattos MG, Ribeiro RF. Effect of different investments and mold temperatures on titanium mechanical properties. J Prosthodont Res. 2012;56:58-64.

15- Seo RS, Murata H, Hong G, Vergani CE, Hamada T. Influence of thermal and mechanical stresses on the strength of intact and relined denture bases. J Prosthet Dent. 2006;96:59-67.

16- Shimizu H, Kurtz KS, Tachii Y, Takahashi Y. Use of metal conditioner to improve bond strengths of autopolymerizing denture base resin to cast Ti-6Al-7Nb and Co-Cr. J Dent. 2006;34:117-22.

17- Takahashi Y, Chai J, Kawaguchi M. Strength of relined denture base polymers subjected to long-term water immersion. Int J Prosthodont. 2000;13:205-8.

18- Tsuchimoto $Y$, Yoshida $Y$, Mine A, Nakamura M, Nishiyama $\mathrm{N}$, Van Meerbeek B, et al. Effect of 4-MET- and 10-MDP-based primers on resin bonding to titanium. Dent Mater J. 2006;25:1204. 
19- Tsuchimoto Y, Yoshida Y, Takeuchi M, Mine A, Yatani H, Tagawa $Y$, et al. Effect of surface pre-treatment on durability of resinbased cements bonded to titanium. Dent Mater. 2006;22:545-52. 20- Watanabe I, Kurtz KS, Kabcenell JL, Okabe T. Effect of sandblasting and silicoating on bond strength of polymer-glass composite to cast titanium. J Prosthet Dent. 1999;82:462-7.

21- Watanabe I, Watanabe E, Yoshida K, Okabe T. Effect of surface contamination on adhesive bonding of cast pure titanium and Ti-6Al-4V alloy. J Prosthet Dent. 1999;81:270-6.

22- Yanagida $H$, Matsumura $H$, Taira $Y$, Atsuta $M$, Shimoe S. Adhesive bonding of composite material to cast titanium with varying surface preparations. J Oral Rehabil. 2002;29:121-6.
23- Yatabe M, Yasuda N, Ai M, Okabe Y. Unpolymerized layer on autopolymerizing, hard reline materials. Int J Prosthodont. 1999;12:129-34.

24- Yoshida T, Terashima N, Niiro T, Nagasawa S, Ito M, Yagasaki $\mathrm{H}$, et al. Bond strength of resin cements to $\mathrm{H}_{2} \mathrm{O}_{2}$-treated titanium plates. Dent Mater. 2005;21:1087-97.

25- Zissis A, Yannikakis S, Polyzois G, Harrison A. A long term study on residual monomer release from denture materials. Eur J Prosthodont Restor Dent. 2008;16:81-4. 